\title{
Дислокационная фотолюминесценция в кремнии, имплантированном ионами германия
}

\author{
(C) Н.А. Соболев ${ }^{1}$, А.Е. Калядин ${ }^{1}$, В.И. Сахаров ${ }^{1}$, И.Т. Серенков ${ }^{1}$, Е.И. Шек ${ }^{1}$, \\ Е.О. Паршин ${ }^{2}$, Н.С. Мелесов ${ }^{2}$, С.Г. Симакин ${ }^{2}$ \\ ${ }^{1}$ Физико-технический институт им. А.Ф. Иоффе Российской академии наук, \\ 194021 Санкт-Петербург, Россия \\ ${ }^{2}$ Ярославский фрилиал Физико-технологического института Российской академии наук, \\ 150007 Ярославль, Россия \\ E-mail: nick@sobolev.ioffe.rssi.ru
}

(Получена 25 июля 2018 г. Принята к печати 13 августа 2018 г.)

\begin{abstract}
Исследовано влияние условий постимплантационного отжига кремния, имплантированного ионами германия, на образование люминесцентных центров. Измерения с помощью метода обратного резерфордовского рассеяния ионов средней и высокой энергий показали, что имплантация ионами германия с энергией $1 \mathrm{MэB} \mathrm{и} \mathrm{дозой} 1.5 \cdot 10^{14} \mathrm{~cm}^{-2}$ не приводит к аморфизации монокристаллического кремния. Обнаружено, что последующий высокотемпературный отжиг имплантированных образцов в хлорсодержащей атмосфере при $1100^{\circ} \mathrm{C}$ в течение 0.5-1.5 ч приводит к образованию так называемых D1 и D2 линий дислокационной люминесценции с длинами волн 1.54 и 1.42 мкм. При увеличении времени отжига интенсивность линии D1 уменьшается, а D2 - остается постоянной, но во всех спектрах доминирует D1 линия. Обсуждаются возможные факторы, приводящие к снижению интенсивности D1 линии, в частности диффузия атомов германия и образование твердого раствора кремний-германий.
\end{abstract}

DOI: 10.21883/FTP.2019.02.47093.8965

\section{1. Введение}

Одним из приоритетных направлений для развития кремниевой оптоэлектроники является создание светодиодов (СД) на длину волны $\sim 1.6$ мкм, что позволит реализовать предложенный Р. Сорефом чип, интегрирующий оптические и электронные приборы на одной подложке и названный оптоэлектронной интегральной схемой [1]. Перспективным путем для создания СД на эту длину волны представляется использование так называемой дислокационной люминесценции (ДЛ). Впервые ДЛ наблюдалась в образцах кремния с большой плотностью дислокаций в работе [2]. Практическое использование ДЛ долгое время сдерживалось отсутствием эффективных способов подавления безызлучательной рекомбинации в таких светоизлучающих структурах (СИС). Развитие эффективных способов геттерирования и водородной пассивации центров безызлучательной рекомбинации позволило изготовить СД с высокой квантовой эффективностью электролюминесценции (ЭЛ) при комнатной температуре и возродило интерес к этой тематике $[3,4]$. Обычно, когда говорят о ДЛ, имеют в виду образование четырех линий D1-D4, длины волн которых при низких температурах равняются 1.53, 1.43, 1.33 и 1.25 мкм. Для практического использования представляет интерес только D1 линия, поскольку она соответствует интересующей длине волны и наблюдается при комнатной температуре. СИС с ДЛ на основе кремния были изготовлены с помощью методов, основанных на деформации кремниевых пластин при изгибе [2] или одноосном сжатии [4], релаксации выращенных на его поверхности эпитаксиальных слоев $\mathrm{SiGe}$ [5], лазерной перекристаллизации [3], жидкофазной эпитаксии [6], облучении быстрыми электронами [7] и ионной имплантации [8]. Из всех перечисленных технологических методов только последний используется в современной технологии изготовления сверхбольших интегральных схем и может быть в нее встроен. При этом следует отметить, что технология обеспечивает однородное распределение структурных дефектов и люминесцентных центров по площади всей имплантируемой пластины и характеризуется высокой воспроизводимостью результатов. Развитие концепции инженерии дефектов в имплантационной технологии позволило установить основные закономерности процесса образования дефектов и выявить особенности, возникающие в спектрах излучения при изменении условий имплантации ионов $\mathrm{Er}, \mathrm{Ho}$ и $\mathrm{Si}$ и последующего отжига [9], а также изготовить СД с дислокационной ЭЛ при комнатной температуре $[9,10]$. Однако для практического использования таких СД актуальным остается вопрос повышения интенсивности ДЛ. Поэтому в последнее время активно проводятся работы, направленные на поиск новых возможностей для развития имплантационного метода. Например, совместная имплантация нескольких ионов [11] или других ионов (германия и фтора) [12-14]. Авторам известны всего две работы $[12,13]$, в которых СИС формировались после имплантации ионов $\mathrm{Ge}$ с дозами, значительно превышающими порог аморфизации кремния, и последующего импульсного отжига с помощью лазерного излучения или ионных пучков. В обеих работах в спектрах ФЛ наблюдались очень широкие линии (полуширина более 100 нм) с максимумом в области $1.55-1.6$ мкм. Повидимому, эти линии представляют собой суперпозиции 
различных линий. Авторы работы [12] утверждают, что появление линии обусловлено формированием квантовых точек SiGe, а вклад от излучения дислокаций незначителен. В работе [13] появление линии связывают с образованием нанокристаллов, дислокаций и преципитатов SiGe. Цель настоящей работы заключалась в исследовании возможности создания СИС с дислокационной люминесценцией с помощью имплантации ионов германия.

\section{2. Методика эксперимента и обсуждение результатов}

В качестве подложек использовались пластины кремния, выращенного методом Чохральского, $p$-типа проводимости $(p-\mathrm{Cz}-\mathrm{Si})$ с удельным сопротивлением 10 Ом · см, толщиной 350 мкм и диаметром 60 мм. Ионы $\mathrm{Ge}$ с энергией $1 \mathrm{MэB}$ имплантировались с дозой $1.5 \cdot 10^{14} \mathrm{~cm}^{-2}$ и плотностью ионного тока $4 \mathrm{HA} / \mathrm{cm}^{2}$ при комнатной температуре. Расчетная длина проецированного пробега ионов равнялась 730 нм. Имплантация проводилась на ускорителе High Voltage Engineering Europe. Пучок ионов направлялся под углом $7^{\circ}$ от нормали к имплантируемой поверхности, чтобы избежать эффекта каналирования.

Концентрация атомов германия измерялась с помощью метода вторичной ионной масс-спектроскопии (SIMS) на установке TOF.SIMS5. На рис. 1 приведен измеренный профиль атомов германия в имплантированном образце. Распределение атомов, рассчитанное с помощью программы SRIM [15], также приведено на рисунке. Видно, что экспериментальный и расчетный профили, а также их основные параметры (положение максимума, максимальная концентрация атомов германия и полуширина распределения) достаточно хорошо (в пределах $\pm 10 \%)$ совпадают.

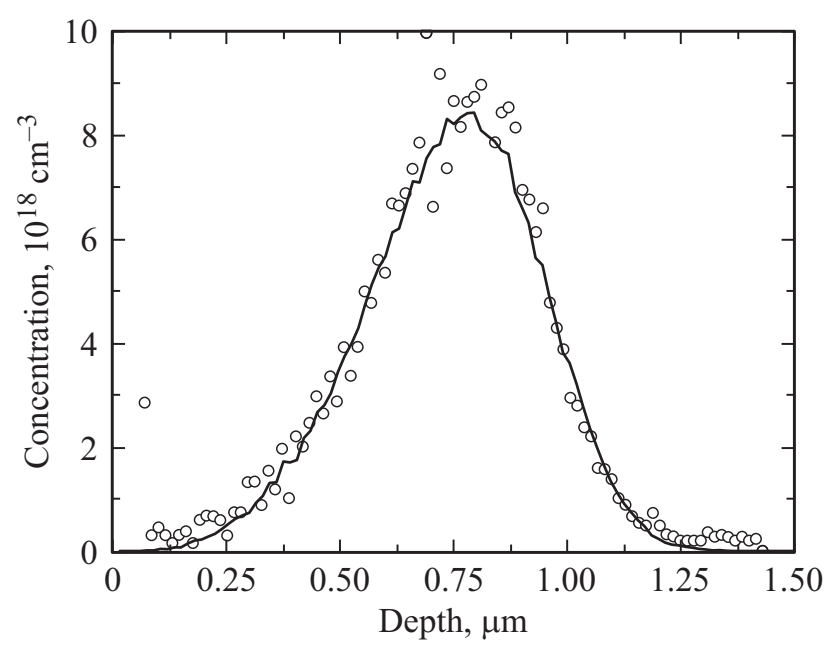

Рис. 1. Концентрационный профиль атомов германия, измеренный методом SIMS (точки) и рассчитанный по программе SRIM-2013 (сплошная линия).
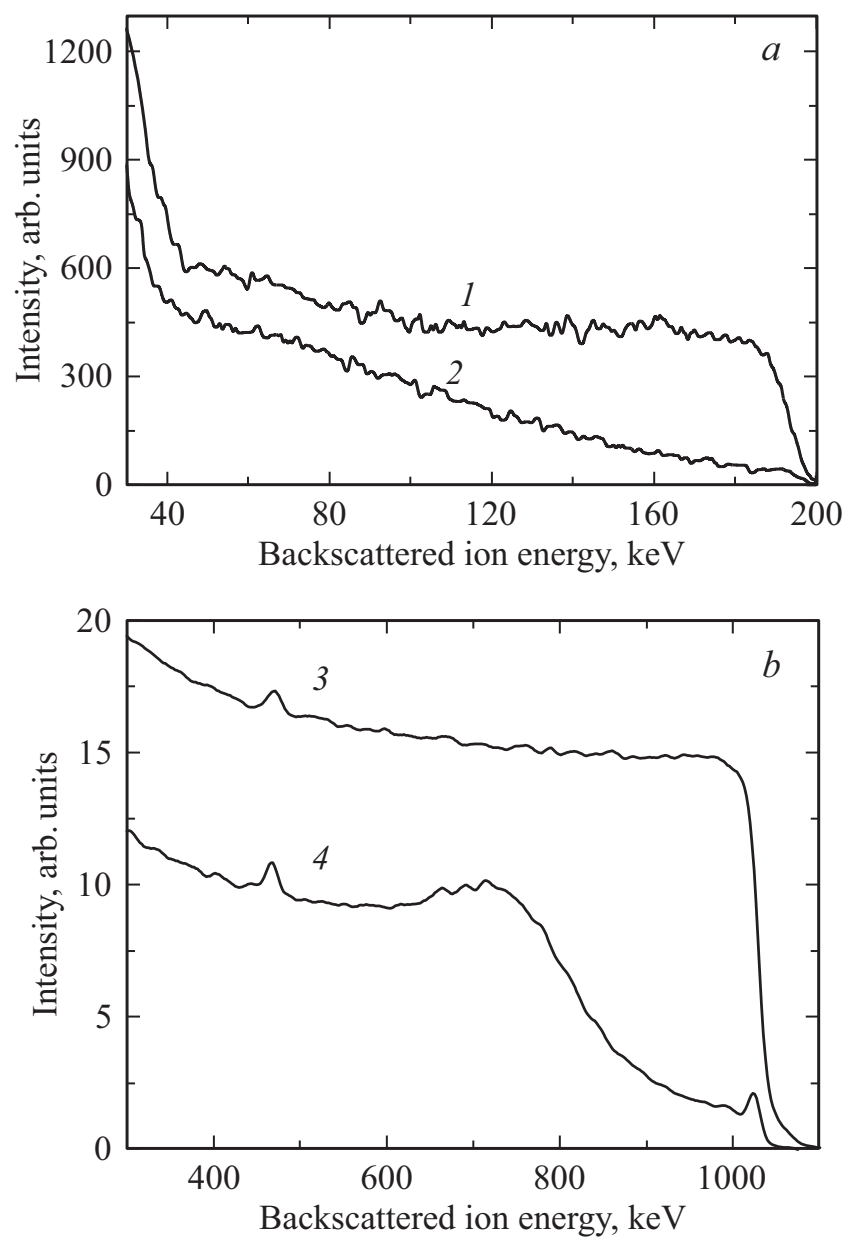

Рис. 2. Спектры RBS ионов, измеренные в случайном (1 и 3 ) и каналирующем (2 и 4 ) режимах для имплантированного $\mathrm{Si}: \mathrm{Ge}$ образца при энергии зондирующих ионов $E$, кэВ: $227(a)$ и $1800(b)$.

Дефектная структура имплантированных слоев исследовалась с помощью метода резерфордовского обратного рассеяния (RBS) протонов с энергией 227 кэВ и ионов гелия с энергией 1800 кэВ. Кремниевые детекторы с энергетическим разрешением 3.5 и 13 кэВ регистрировали ионы, рассеянные на углы 170 и $160^{\circ}$ соответственно. Измерение энергетических спектров обратнорассеянных ионов проводилось в режимах каналирования и псевдослучайного направления пучка (далее каналирующий и случайный режимы). Спектры RBS ионов средней и высокой энергий в имплантированных образцах приведены на рис. 2, $a$ и $b$ соответственно. Кривые 1,3 и 2,4 были измерены в случайном и каналирующем режимах. Анализ спектров показывает, что аморфизации имплантированного слоя не происходит: интенсивность случайного сигнала во всем диапазоне измерений выше, чем у каналирующего.

Постимплантационный отжиг осуществлялся в хлорсодержащей атмосфере при температуре $1100^{\circ} \mathrm{C}$ длительностью $0.5-1.5$ ч. Хлорсодержащая атмосфера пред- 

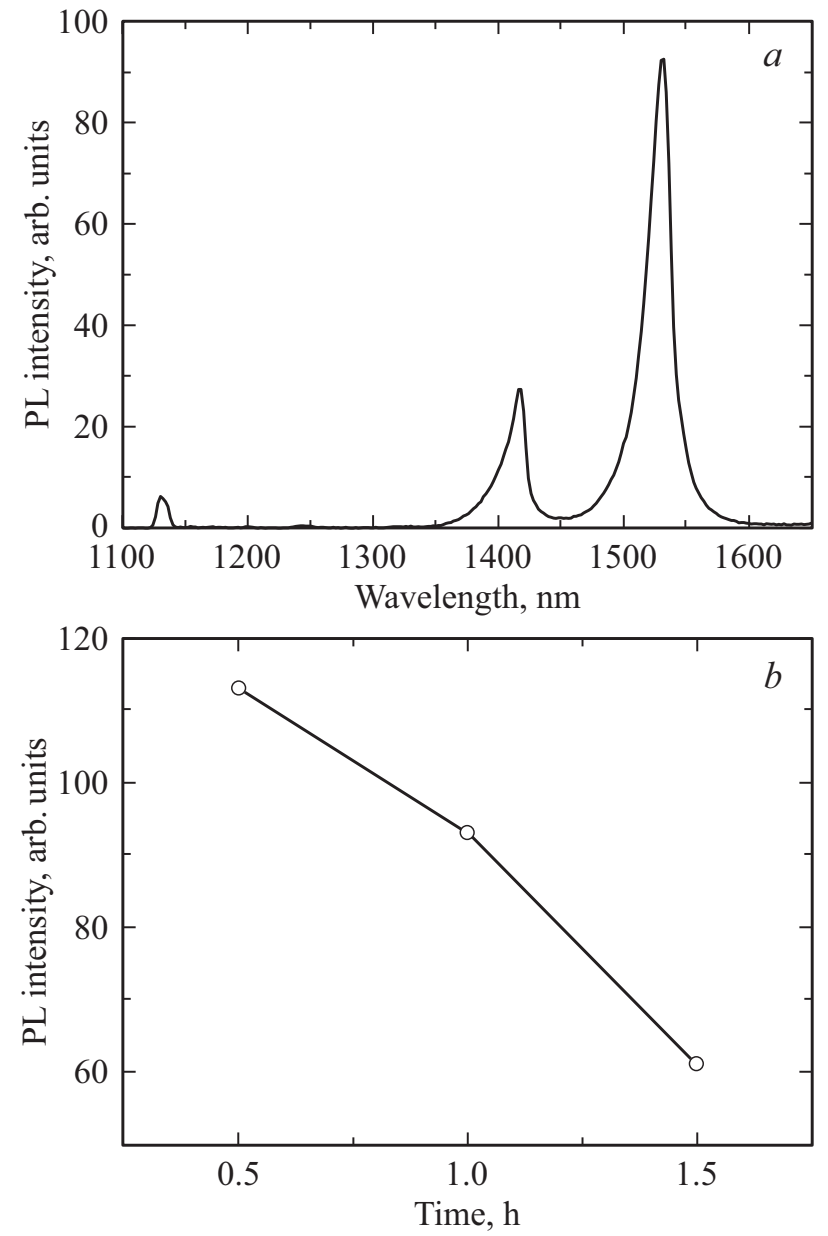

Рис. 3. Измеренный при $10 \mathrm{~K}$ спектр ФЛ после отжига в течение 1 ч $(a)$. Зависимость интенсивности D1 линии от времени отжига $(b)$.

ставляла собой поток кислорода, насыщенный парами четыреххлористого углерода с молярной концентраций $1 \%$. Фотолюминесценция (ФЛ) возбуждалась твердотельным лазером на длине волны 532 нм и регистрировалась в диапазоне длин волн $1-1.65$ мкм при температуре $10 \mathrm{~K}$ с помощью автоматизированного монохроматора МДР-25 и InGaAs-фотоприемника. Спектральное разрешение системы составляло 7 нм. Спектр ФЛ образца после имплантации ионов Ge и отжига в течение 1 ч представлен на рис. 3, $а$. Наблюдаются две линии с максимумами при 1.54 и 1.42 мкм, принадлежащие D1 и D2 центрам ДЛ. Полуширины этих линий составляют $\sim 16 \mathrm{Hм}$, что соответствует их значениям в образцах, полученных с помощью других технологических методов [9]. Спектры ФЛ после отжигов при других длительностях аналогичны приведенному спектру на рис. 3,a. Наличие линий ДЛ во всех исследованных образцах обусловлено тем, что имплантация ионов $\mathrm{Ge}$ и последующий отжиг приводят к введению протяженных структурных дефектов (дислокационных петель и/или дислокаций), которые образуют или способствуют обра- зованию оптически активных центров. Важно отметить, что, как и в случае имплантации ионов $\mathrm{Er}, \mathrm{O}, \mathrm{Si}$ и F $[9-11,14]$, происходит образование только центров D1 и D2 и не наблюдается появление других связанных с введением дислокаций линий, например, D3 и D4, которые появляются дополнительно в случаях деформации $[2,4]$ или облучения быстрыми электронами [7]. Зависимость интенсивности доминирующей линии D1 от времени отжига показана на рис. $3, b$. С увеличением времени отжига от 0.5 до 1.5 ч наблюдается заметное уменьшение интенсивности линии D1, а интенсивность D2 линии меньше, чем у D1, и практически не изменяется. Температурное гашение интенсивности D1 линии, по-видимому, связано с уменьшением концентрации люминесцентных центров из-за диффузии атомов $\mathrm{Ge}$ и/или образования твердого раствора $\mathrm{SiGe}$, как это наблюдалось в [13]. В спектрах ФЛ с увеличением длительности отжигов наблюдалось увеличение интенсивности линии краевой люминесценции (длина волны 1.13 мкм), что свидетельствует об уменьшении концентрации центров безызлучательной рекомбинации, которые могли бы приводить к падению интенсивности D1 линии.

\section{3. Заключение}

Таким образом, установлено, что имплантация ионов $\mathrm{Ge}$ в исследованных экспериментальных условиях не сопровождается аморфизацией имплантированного слоя кремния. Последующая высокотемпературная обработка в условиях пересыщения кремния собственными межузельными атомами сопровождается отжигом введенных при имплантации радиационных дефектов и образованием оптически активных центров D1 и D2. Важно отметить, что происходит образование только центров D1 и D2 и не наблюдается введение других связанных с протяженными дефектами линий. Интенсивность D1 линии уменьшается со временем отжига, тогда как интенсивность D2 линии остается неизменной. В спектрах также наблюдается линия краевой люминесценции, интенсивность которой нарастает при увеличении длительности отжига. Представляется, что имплантация ионов $\mathrm{Ge}$ с атомным радиусом, значительно превышающим размеры $\mathrm{Si}$-радиуса, может быть перспективной для создания СД с высокой интенсивностью D1 линии дислокационной люминесценции.

Ионная имплантация, а также измерения с помощью методов RBS ионов высокой энергии и SIMS проводились на оборудовании ЦКП „Диагностика микро- и наноструктур“ (ЯФ ФТИАН РАН).

\section{Список литературы}

[1] R.A. Soref. Proc. IEEE, 81, 1687 (1993).

[2] Н.А. Дроздов, А.А. Патрин, В.Д. Ткачев. Письма ЖЭТФ, 23, 651 (1976). 
[3] E.O. Sveinbjornsson, J. Weber. Appl. Phys. Lett., 69, 2686 (1996).

[4] V. Kveder, V. Badylevich, E. Steinman, A. Izotov, M. Zeibt, W. Schreter. Appl. Phys. Lett., 84, 2106 (2004).

[5] S. Fukatsu, Y. Mera, M. Inoue, K. Maeda, H. Akiyama, H. Sakaki. Appl. Phys. Lett., 68, 1889 (1996).

[6] S. Binetti, M. Donghi, S. Pizzini, A. Castaldini, A. Cavallini, F. Fraboni, N.A. Sobolev. Sol. St. Phenomena, 57-58, 197 (1997).

[7] N.A. Sobolev, A.E. Kalyadin, E.I. Shek, K.F. Shtel'makh, A.K. Gutakovskii, V.I. Vdovin, A.N. Mikhaylov, D.I. Tetel'baum, D. Lie, D. Yang, L.I. Fedina. Materials Today: Proceedings, 5, 14772 (2018).

[8] R.H. Uebbing, P. Vagner, H. Baumgart, H.J. Queisser. Appl. Phys. Lett., 37, 1078 (1980).

[9] Н.А. Соболев. ФТП, 10, 23 (2010).

[10] Н.А. Соболев, А.Е. Калядин, М.В. Коновалов, П.Н. Аруев, В.В. Забродский, Е.И. Шек, К.Ф. Штельмах, А.Н. Михайлов, Д.И. Тетельбаум. ФТП, 50, 241 (2016).

[11] А.Н. Терещенко, Д.С. Королев, А.Н. Михайлов, А.И. Белов, А.А. Никольская, Д.А. Павлов, Д.И. Тетельбаум, Э.А. Штейнман. ФТП, 52, 702 (2018).

[12] Ю.Н. Пархоменко, А.И. Белогорохов, Н.Н. Герасименко, А.И. Иржак, М.Г. Лисаченко. ФТП, 38, 593 (2004).

[13] Р.И. Баталов, Р.М. Баязитов, В.И. Нуждин, П.И. Гайдук, С.Л. Прокопьев, Г.Д. Ивлев. Изв. вузов. Физика, № 1/2, 59 (2011).

[14] Н.А. Соболев, А.Е. Калядин, В.И. Сахаров, И.Т. Серенков, Е.И. Шек, К.В. Карабешкин, П.А. Карасев, А.И. Титов. Письма ЖТФ, 43 (1), 14 (2017).

[15] J.F. Ziegler, J.P. Biersack, U. Littmark.The Stopping and Range of Ions in Solids (Pergamon Press, N.Y., 1985).

\section{Dislocation-Related Photoluminescence in Silicon Implanted with Germanium Ions}

\author{
N.A. Sobolev ${ }^{1}$, A.E. Kalyadin ${ }^{1}$, V.I. Sakharov ${ }^{1}$, \\ I.T. Serenkov ${ }^{1}$, E.I. Shek ${ }^{1}$, E.O. Parshin ${ }^{2}$, \\ N.S. Melesov², C.G. Simakin ${ }^{2}$ \\ ${ }^{1}$ loffe Institute, \\ 194021 St. Petersburg, Russia \\ 2 Yaroslavl Branch of the Institute \\ of Physics and Technology, \\ Russian Academy of Sciences, \\ 150007 Yaroslavl, Russia
}

Abstract Influence of conditions of postimplantation annealing of silicon implanted with germanium ions on formation of luminescence centers is studied. Measurements by the technique of Rutherford backscattering of medium and high energy ions show that the implantation of $1 \mathrm{MeV}$ germanium ions at a dose of $1.4 \cdot 10^{14} \mathrm{~cm}^{-2}$ does not result in amorphization of a single crystal silicon. It is revealed that a subsequent high temperature annealing of implanted samples in a chlorine-containing atmosphere at a temperature of $1100^{\circ} \mathrm{C}$ for $0.5-1.5 \mathrm{~h}$ leads to the formation of the so-called D1 and D2 dislocation-related luminescence lines with wavelengths of 1.54 and $1.42 \mu \mathrm{m}$. With increasing annealing duration, the D1 line intensity decreases and the D2 one is constant, but the D1 line dominates in all the spectra. Possible factors responsible for a decrease of the D1 line intensity, in particular germanium atom diffusion and formation of a silicon-germanium solid solution, are discussed.

Редактор Г.А. Оганесян 